\title{
A Validation Study of the Japanese Version of the Addenbrooke's Cognitive Examination-Revised
}

\author{
Kelssy Hitomi dos Santos Kawata ${ }^{a}$ Ryusaku Hashimoto ${ }^{a, b}$ \\ Yoshiyuki Nishio $^{a}$ Atsuko Hayashi $^{a}$ Nanayo Ogawa ${ }^{a}{ }^{\text {b }}$ \\ Shigenori Kanno ${ }^{a}$ Kotaro Hiraoka ${ }^{a, c}$ Kayoko Yokoi ${ }^{a}$ \\ Osamu lizuka ${ }^{a}$ Etsuro Mori ${ }^{a}$
}

a Department of Behavioral Neurology and Cognitive Neuroscience, Tohoku University Graduate School of Medicine, Sendai, ${ }^{b}$ Department of Speech, Language and Hearing Sciences, Health Sciences University of Hokkaido, Sapporo, and ' Division of Cyclotron Nuclear Medicine, Department of Diagnostic Radiology, Cyclotron and Radioisotope Center (CYRIC), Tohoku University, Sendai, Japan

\section{Key Words}

Addenbrooke's Cognitive Examination-Revised • Mini-Mental State Examination • Dementia • Screening $\cdot$ Validity $\cdot$ Reliability $\cdot$ Diagnostic accuracy $\cdot$ Normative data

\begin{abstract}
The aim of this study was to validate the Japanese version of the Addenbrooke's Cognitive Examination-Revised (ACE-R) [Mori: Japanese Edition of Hodges JR's Cognitive Assessment for Clinicians, 2010] designed to detect dementia, and to compare its diagnostic accuracy with that of the Mini-Mental State Examination. The ACE- $R$ was administered to 85 healthy individuals and 126 patients with dementia. The reliability assessment revealed a strong correlation in both groups. The internal consistency was excellent $(\alpha$-coefficient $=0.88)$. Correlation with the Clinical Dementia Rating sum of boxes score was significant $\left(r_{s}=-0.61, p<0.001\right)$. The area under the curve was 0.98 for the ACE-R and 0.96 for the Mini-Mental State Examination. The cut-off score of 80 showed a sensitivity of $94 \%$ and a specificity of $94 \%$. Like the original ACE-R and the versions designed for other languages, the Japanese version of the ACE- $R$ is a reliable and valid test for the detection of dementia.




\section{Introduction}

The early diagnosis of dementia is of great importance for providing patients with the appropriate medical and social interventions. The Mini-Mental State Examination (MMSE), a widely used screening test for dementia [2], can distinguish dementia patients from cognitively healthy individuals and has achieved acceptable sensitivity and specificity in detecting dementia [3, 4]. However, the MMSE has limitations in screening multiple cognitive domains and in detecting early dementia of disorders, such as frontotemporal dementia. The Addenbrooke's Cognitive Examination (ACE) was developed to be a brief test that is sensitive to indicators of the early stages of dementia and differentiates between dementia subtypes [5]. A revised version of the ACE (ACE-R) [6] provides a brief bedside cognitive assessment scale and has been reported to be useful for the early detection of dementia and for discerning Alzheimer's disease (AD) from frontotemporal dementia.

The ACE-R examines key aspects of cognition and can be administered without special testing equipment or trained personnel [6]. This brief cognitive screening test incorporates elements of the MMSE, expanding the memory, language and visuospatial components and adding a verbal fluency component. The ACE-R involves five cognitive domains: attention/ orientation (18 points), memory (26 points), verbal fluency (14 points), language (26 points) and visuospatial components ability (16 points), adding up to a maximum total score of 100 . Higher scores indicate higher levels of cognitive functioning. The ACE-R has been translated into several languages, and validation has been performed for the different versions of the ACE-R in several countries [6-12]. The aim of this study was to validate the reliability of the Japanese version of the ACE-R [1] for detecting dementia, to compare its diagnostic accuracy with that of the MMSE and to investigate the performance of healthy individuals in the ACE-R total and subdomain scores.

\section{Methods}

\section{Adaptation of the ACE-R from English to Japanese}

The ACE-R was translated into Japanese with cultural and linguistic adaptations, and the orientation/attention subtest is identical to that in the Japanese MMSE [13]. Three questions in the retrograde memory subtest were changed based on the same period of occurrence of the original ACE-R. The name of the current Prime Minister of the UK was replaced with that of the Prime Minister of Japan. The questions about a female prime minister of the UK and a US president who was assassinated were replaced by questions about the national singer of the Showa period (Hibari Misora) and the Japanese Prime Minister involved in the Lockheed bribery scandal (Kakuei Tanaka), respectively. In the verbal fluency subtest, the letter ' $\mathrm{p}$ ' was replaced with the syllable ' $\mathrm{ka}$ ' because the Japanese language is based on syllables rather than phonemes. We derived the scaled scoring systems for letter and category fluency based on the averages and standard deviations determined for the elderly Japanese population [14]. The words in the repetition subtest were selected according to the criteria used in the original English ACE-R: length, frequency and difficulty to articulate. In the naming subtest, six line-drawings of animals or objects that are less familiar to Japanese were replaced based on the familiarity rating for Snodgrass's line-drawings [15]. The 'kangaroo', 'penguin' and 'crocodile' drawings were replaced with 'sea horse', 'owl' and 'peak' drawings, respectively. The 'harp', 'barrel' and 'crown' drawings were replaced with 'cigar', 'baby carriage' and 'helicopter' drawings, respectively. In the comprehension subtest, the questions were changed in accordance with the replaced line-drawings. The reading subtest, which was designed to detect surface dyslexic reading errors, was adapted to maintain the irregularity 
of words similar to the original ACE-R. The Japanese language uses many compound Kanji words consisting of two or three Kanji characters, each with one or two syllables. In the subtest, however, we used two- or three-character stimuli, which do not abide by the reading rules and cannot be pronounced without semantics. [Japanese semantic dementia patients, whose reading disorders are surface dyslexic, usually pronounce Kanji words according to the regular rules. For example, they sometimes read 田舎 [i-na-ka] (rural) in our stimuli as 田+舎 [ta-sha] (no meaning).] In the perceptual abilities subtest, four Katakana letters (Japanese syllabograms) replaced English letters with similar geometric complexity. An alternative $B$ version of the ACE-R had different name and address stimuli for the recall subtests to prevent recalling from the previous A version. We have published the Japanese version in a book as an appendix [1].

\section{Participants}

This study received approval from the Research Ethics Committee of Tohoku University Hospital. All participants gave their informed consent to participate in this study and were treated according to the Declaration of Helsinki. The ACE-R was applied to a population living in the prefecture of Miyagi (northeastern Japan) between June 2010 and March 2011. All participants were between 50 and 90 years old, had normal or corrected-to-normal visual acuity and had no audition problems.

\section{Dementia Group}

We recruited 126 patients from the memory clinics of Tohoku University Hospital and the affiliated hospitals (Saito Hospital, Minami Tohoku Hospital and Miyagi Hospital). The subjects included 92 women and 34 men with a mean age of $77.3 \pm 7.6$ years and a mean educational achievement of $10.6 \pm 2.5$ years. The clinical assessment included laboratory tests, neuropsychological assessment and structural neuroimaging (CT and/or MRI). We used the DSM-III R criteria for dementia [16] and the following criteria for specific diagnoses: the NINCDS-ADRDA for probable AD [17], the frontotemporal lobar degeneration (FTLD) consensus criteria [18], the Consortium on Dementia with Lewy Bodies (DLB) criteria [19], the MDS Task Force criteria for Parkinson's disease with dementia [20], the NINDS-SPSP criteria for progressive supranuclear palsy (PSP) [21] and the Lang criteria for corticobasal degeneration [22]. The severity of dementia was assessed using the Clinical Dementia Rating (CDR) [23], and patients with very mild to moderate dementia were included. The clinical diagnoses were established independently of the participants' performance on the ACE-R. The dementia group consisted of subjects diagnosed with AD $(n=79)$, DLB $(n=31)$, FTLD $(n=9)$, Parkinson's disease with dementia $(n=3)$, PSP $(n=2)$ and corticobasal degeneration $(n=2)$.

\section{Healthy Controls}

We recruited 85 healthy subjects at the two centers for the welfare of the elderly program or among the patients' spouses. We excluded patients who had a history of head injury, drug abuse, alcoholism or neurologic complaints. The control group included 51 women and 34 men with a mean age of $71.5 \pm 9.1$ years and a mean educational achievement of $12.3 \pm 2.6$ years.

\section{Procedures and Data Analysis}

The normative data scores were divided into four age groups (50-64, 65-74, 75-79 and 80-85 years) and described using one-way analysis of variance (ANOVA). Post-hoc pair-wise comparisons between the age ranges were assessed by using the Bonferroni correction. Multiple regression analyses were performed to assess the influence of age, education and sex on the participants' performance in the total and subdomain ACE-R scores. 

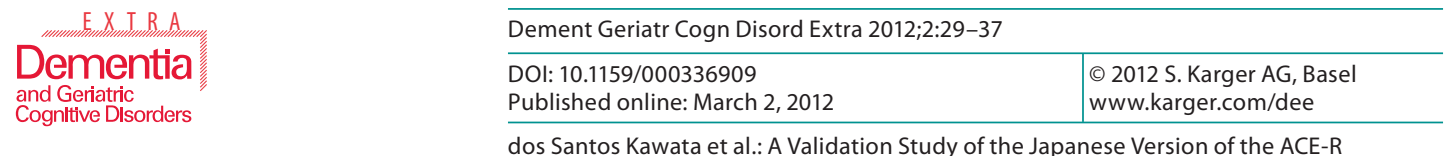

Table 1. Normative data for the total ACE-R score and subscores for Japanese subjects according to age group (mean \pm SD)

\begin{tabular}{lllllllll}
\hline Age group & $\begin{array}{l}\text { Patients } \\
\mathrm{n}\end{array}$ & $\begin{array}{l}\text { Education } \\
\text { years }\end{array}$ & $\begin{array}{l}\text { Total ACE-R } \\
\text { score }\end{array}$ & $\begin{array}{l}\text { Attention/ } \\
\text { orientation } \\
\text { subscore }\end{array}$ & $\begin{array}{l}\text { Memory } \\
\text { subscore }\end{array}$ & $\begin{array}{l}\text { Fluency } \\
\text { subscore }\end{array}$ & $\begin{array}{l}\text { Language } \\
\text { subscore }\end{array}$ & $\begin{array}{l}\text { Visuospatial } \\
\text { subscore }\end{array}$ \\
\hline $50-64$ years & 22 & $13.7 \pm 2.9$ & $95.3 \pm 5.2$ & $17.9 \pm 0.3$ & $23.4 \pm 3.2$ & $13.3 \pm 1.7$ & $24.9 \pm 2.1$ & $15.8 \pm 0.5$ \\
$65-74$ years & 19 & $12.0 \pm 2.3$ & $91.1 \pm 8.4$ & $17.5 \pm 1.2$ & $21.0 \pm 4.8$ & $12.3 \pm 2.0$ & $24.3 \pm 1.7$ & $15.9 \pm 0.2$ \\
$75-79$ years & 31 & $12.2 \pm 2.0$ & $88.5 \pm 6.7$ & $17.4 \pm 0.8$ & $19.8 \pm 4.1$ & $12.1 \pm 1.9$ & $23.4 \pm 1.9$ & $15.8 \pm 0.5$ \\
$80-85$ years & 13 & $10.4 \pm 2.3$ & $88.0 \pm 3.4$ & $17.8 \pm 0.4$ & $18.4 \pm 2.9$ & $11.7 \pm 2.5$ & $24.3 \pm 1.5$ & $15.8 \pm 0.4$ \\
\hline
\end{tabular}

The reliability of the scale was assessed by two methods: (1) the intraclass correlation coefficient (ICC) for the interrater test-retest reproducibility using alternative versions repeated after a mean interval of 2 months (the fixed order was version A followed by version B) in a subset of 13 dementia patients and 19 healthy controls, and (2) Cronbach's alpha coefficient for the internal consistency. The concurrent validity was assessed using the Spearman rho correlation between the ACE-R and the CDR sum of boxes (CDR-SOB) score in the dementia group.

The demographic data and the ACE-R total, subdomain and MMSE (ACE-R) scores of the dementia and control groups were compared using one-way ANOVA. The diagnostic accuracy was assessed by receiver operating characteristic (ROC) analysis, which permits the calculation of the overall test performance by considering the sensitivity/specificity pairs for every possible threshold of a test. The resulting ROC curve can be used for the estimation of the optimal cutoff according to the costs of the false-positive and false-negative results. In the present study, the optimal cutoff was defined as the point on the ROC curve where the product of the corresponding sensitivity/specificity pair reached the maximum value. The area under the ROC curve was used as an indicator of test performance and was calculated using nonparametric methods. All of the statistical analyses were performed using SPSS version 1.9 (IBM SPSS Inc.). The level of statistical significance was set at $\mathrm{p}<0.05$.

\section{Results}

The administration of the Japanese version of the ACE- $\mathrm{R}$ required $28.8 \pm 10.5 \mathrm{~min}$ (range 15-63) for the dementia group and $17.0 \pm 3.6 \mathrm{~min}$ (range 12-30) for the control group.

\section{Normative Data}

Table 1 summarizes the age-specific performance of the healthy controls, who were divided into four age groups, in the total ACE-R and the subdomains.

ANOVA revealed a significant effect of age on the total score $(F=5.68, p<0.01)$, memory $(\mathrm{F}=5.60, \mathrm{p}<0.01)$ and language $(\mathrm{F}=2.86, \mathrm{p}=0.04)$. The subjects of the $75-79$ and $80-$ 85 age ranges had significantly lower ACE-R total, memory and language scores compared to those of the 50-64 age group. Younger individuals had higher ACE-R total, memory and verbal fluency scores than older individuals in the control group.

In the multiple linear regression analysis, the ACE-R total score or the subdomain scores were entered into the multiple regression model together with possible confounds that included age, education level and sex. There were significant effects of age on the ACE$\mathrm{R}$ total score (partial $\mathrm{r}=-0.28, \mathrm{p}=0.01$ ) and memory subscales (partial $\mathrm{r}=-0.29, \mathrm{p}=0.01$ ), of education on the ACE-R total score (partial $\mathrm{r}=0.31, \mathrm{p}<0.01$ ), memory subscale (partial 
Fig. 1. Scatterplot of ACE-R total scores indicates the dementia severity.

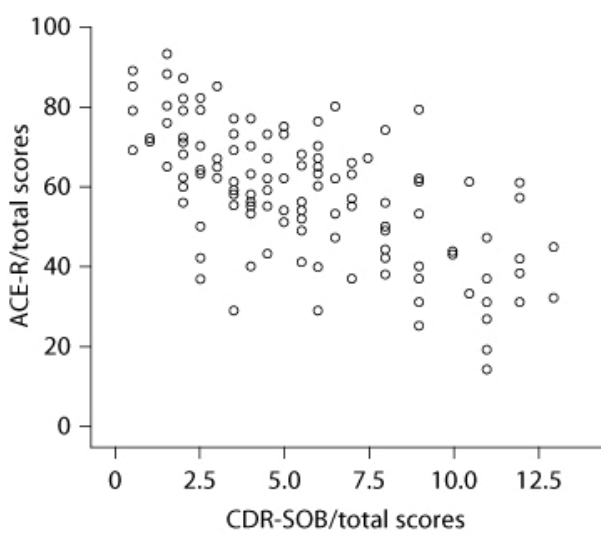

$\mathrm{r}=0.30, \mathrm{p}=0.01)$ and language subscale (partial $\mathrm{r}=0.26, \mathrm{p}=0.02)$, and of sex on the ACE$\mathrm{R}$ total score (partial $\mathrm{r}=0.28, \mathrm{p}=0.01$ ) and verbal fluency subscale (partial $\mathrm{r}=0.29, \mathrm{p}=$ $0.01)$.

\section{Reliability and Validity}

The mean interval between the test and retest was $60 \pm 17.3$ days. The ICC was strong $(r=0.77)$ for healthy controls and very strong $(r=0.90)$ for patients with dementia. Cronbach's alpha coefficient for the ACE- $\mathrm{R}$ was 0.88 , indicating an excellent internal consistency. There was a considerably high correlation between the ACE-R total score and the CDR-SOB score in the dementia group $\left(r_{s}=-0.61\right.$, two-tailed, $\left.\mathrm{p}<0.01\right)$ (fig. 1$)$.

\section{Diagnostic Accuracy}

The results of one-way ANOVA showed the statistical differences in age $(\mathrm{F}=24.6, \mathrm{p}<$ $0.01)$, education level $(\mathrm{F}=22.0, \mathrm{p}<0.01)$ and $\operatorname{sex}(\mathrm{F}=3.9, \mathrm{p}=0.05)$ between the healthy controls and the patients. A similar set of analyses confirmed significant group effects on the mean scores of the ACE-R total, subdomains and MMSE (ACE-R) (table 2).

The difference in ACE-R total score between the healthy controls and the dementia group was statistically significant $(\mathrm{F}=295.5, \mathrm{p}<0.01)$. Significant group differences were also found in orientation/attention $(\mathrm{F}=158.7, \mathrm{p}<0.01)$, memory $(\mathrm{F}=490.0, \mathrm{p}<0.01)$, verbal fluency $(\mathrm{F}=142.3, \mathrm{p}<0.01)$, language $(\mathrm{F}=89.0, \mathrm{p}<0.01)$, visuospatial $(\mathrm{F}=63.8, \mathrm{p}<0.01)$ and MMSE scores $(\mathrm{F}=208.1, \mathrm{p}<0.01)$. Given the significant differences caused by age, education and sex, these variables were included as covariates in an analysis of covariance (ANCOVA) between the healthy controls and the dementia patients. ANCOVA showed a highly significant difference between groups for the ACE-R total $(\mathrm{F}=233.9, \mathrm{p}<0.01)$, subdomains [orientation/attention $(\mathrm{F}=131.2, \mathrm{p}<0.01)$, memory $(\mathrm{F}=390.9, \mathrm{p}<0.01)$, verbal fluency $(\mathrm{F}=$ $103.5, \mathrm{p}<0.01)$, language $(\mathrm{F}=62.7, \mathrm{p}<0.01)$ and visuospatial $(\mathrm{F}=61.0, \mathrm{p}<0.01)]$ and MMSE $(\mathrm{ACE}-\mathrm{R})(\mathrm{F}=170.6, \mathrm{p}<0.01)$.

The significant differences due to age, education and sex were confirmed by ANOVA (table 2) and ANCOVA with years of education as the covariate $(\mathrm{p}<0.05)$. The patients were matched one to one to the healthy controls on the basis of age (within 2 years), education level (within 1 year) and sex. Of the 85 healthy controls, 49 (mean age $74.9 \pm 7.1$ years, range 52-85; mean education $11.7 \pm 1.9$ years, range $8-17)$ were matched with subjects 
Table 2. Demographic data and neuropsychological test scores (mean \pm SD)

\begin{tabular}{|c|c|c|c|c|c|c|}
\hline & \multicolumn{3}{|c|}{ Original sample } & \multicolumn{3}{|c|}{ Case-controlled sample } \\
\hline & $\begin{array}{l}\text { controls } \\
(\mathrm{n}=85)\end{array}$ & $\begin{array}{l}\text { dementia } \\
(\mathrm{n}=126)\end{array}$ & $\mathrm{p}$ & $\begin{array}{l}\text { controls } \\
(\mathrm{n}=49)\end{array}$ & $\begin{array}{l}\text { dementia } \\
(\mathrm{n}=49)\end{array}$ & $\mathrm{p}$ \\
\hline Male/female & $34 / 51$ & $34 / 92$ & $<0.005$ & $16 / 33$ & $16 / 33$ & 1 \\
\hline Age, years & $71.5 \pm 9.1$ & $77.3 \pm 7.6$ & $<0.01$ & $74.9 \pm 7.1$ & $75.1 \pm 7.0$ & 0.88 \\
\hline Education, years & $12.3 \pm 2.6$ & $10.6 \pm 2.5$ & $<0.01$ & $11.7 \pm 1.9$ & $11.6 \pm 1.8$ & 0.83 \\
\hline MMSE score (max. 30) & $28.6 \pm 1.4$ & $21.1 \pm 4.7$ & $<0.01$ & $28.5 \pm 1.3$ & $22.1 \pm 4.3$ & $<0.01$ \\
\hline Total ACE-R score (max. 100) & $90.8 \pm 6.9$ & $58.4 \pm 16.4$ & $<0.01$ & $89.5 \pm 6.2$ & $62.5 \pm 15.4$ & $<0.01$ \\
\hline Orientation/attention (max. 18) & $17.6 \pm 0.8$ & $12.9 \pm 3.4$ & $<0.01$ & $17.6 \pm 0.7$ & $13.7 \pm 3.3$ & $<0.01$ \\
\hline Memory (max. 26) & $20.8 \pm 4.2$ & $7.4 \pm 4.4$ & $<0.01$ & $20.0 \pm 3.9$ & $7.9 \pm 4.5$ & $<0.01$ \\
\hline Verbal fluency (max. 14) & $12.4 \pm 2.0$ & $7.1 \pm 3.8$ & $<0.01$ & $12.1 \pm 2.1$ & $7.7 \pm 3.5$ & $<0.01$ \\
\hline Language (max. 26) & $24.1 \pm 1.9$ & $18.4 \pm 5.4$ & $<0.01$ & $23.9 \pm 1.8$ & $19.6 \pm 5.1$ & $<0.01$ \\
\hline Visuospatial (max. 16) & $15.8 \pm 0.5$ & $12.7 \pm 3.6$ & $<0.01$ & $15.8 \pm 0.5$ & $13.5 \pm 2.8$ & $<0.01$ \\
\hline
\end{tabular}

Table 3. Optimal cut-off scores for screening tests

\begin{tabular}{lll}
\hline & ACE-R & MMSE \\
\hline Cut-off score & 80 & 25 \\
Sensitivity* & $0.94 / 0.94$ & $0.98 / 0.98$ \\
Specificity* & $0.94 / 0.92$ & $0.87 / 0.80$ \\
AUC $^{*}$ & $0.98 / 0.97$ & $0.96 / 0.94$ \\
\hline
\end{tabular}

* Original sample/case-controlled sample.

from the dementia group (mean age $75.1 \pm 7.0$ years, range 52-85; mean education 11.6 \pm 1.8 years, range $8-16)$. The patient subgroups included AD $(n=35)$, DLB $(n=9)$, FTLD $(\mathrm{n}=4)$ and PSP $(\mathrm{n}=1)$. Separate one-way ANOVA tests showed no significant differences according to age $(\mathrm{F}=0.03, \mathrm{p}=0.88)$ or education $(\mathrm{F}=0.05, \mathrm{p}=0.83)$. However, ANOVA revealed significant effects of the ACE- $\mathrm{R}$ total $(\mathrm{F}=129.54, \mathrm{p}<0.01)$, orientation/attention $(\mathrm{F}=63.39, \mathrm{p}<0.01)$, memory $(\mathrm{F}=198.01, \mathrm{p}<0.01)$, verbal fluency $(\mathrm{F}=57.87, \mathrm{p}<0.01)$, language $(\mathrm{F}=31.55, \mathrm{p}<0.01)$, visuospatial $(\mathrm{F}=31.09, \mathrm{p}<0.01)$ and MMSE $(\mathrm{ACE}-\mathrm{R})(\mathrm{F}=$ 95.73, $\mathrm{p}<0.01)$.

Two ROC curves were estimated from the scores of the ACE-R and the MMSE (ACE-R), which are presented in figure 2.

The area under the curve (AUC) was 0.98 for the ACE-R and 0.96 for the MMSE. Although the AUC for the ACE-R was slightly superior to that for the MMSE, this difference was not statistically significant. The optimal cut-off point of the ACE-R was 80 , which yielded a score of $94 \%$ for both sensitivity and specificity (table 3 ).

After adjusting for the differences in age, education and sex, the analysis of the diagnostic accuracy was repeated on the case-controlled samples. The AUC values (ACE-R 0.97 and MMSE 0.94) and the optimal cut-off point of the ACE-R were similar (94\% for sensitivity and $92 \%$ for specificity) to the values determined in the original sample. 
Fig. 2. ROC curve of the MMSE and ACE-R as tests for detecting dementia. Diagonal segments are produced by ties.

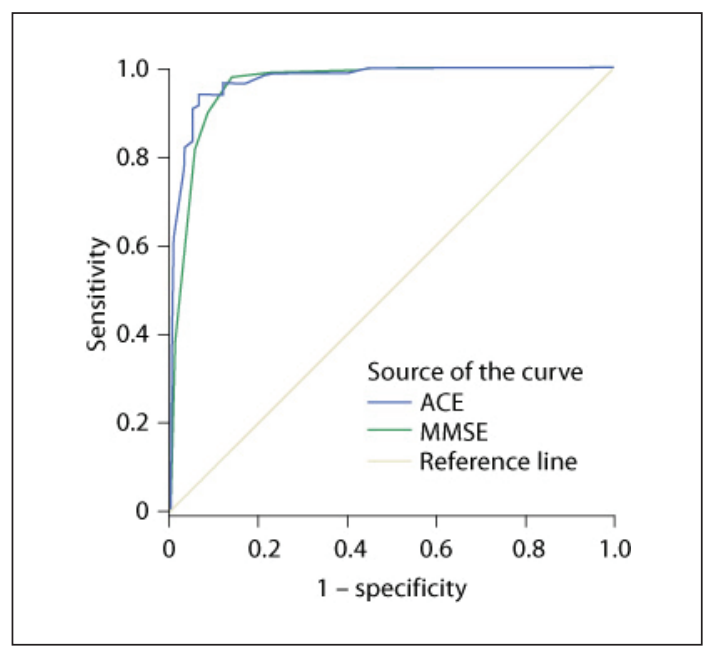

\section{Discussion}

The present study demonstrates that the Japanese version of the ACE-R has a high testretest reliability, a satisfactory level of internal consistency, a good correlation with the CDRSOB and a high diagnostic accuracy. These findings confirm that the Japanese version of the ACE- $\mathrm{R}$ is a reliable and valid tool for the assessment of dementia. This test can be administered in a short time period, similar to other versions of the ACE-R that have been adapted to different languages $[6-9,11]$.

In this study, the reliability was tested according to the test-retest reliability, interrater reliability and internal consistency. Even though the test-retest was performed by different raters using alternative versions, which is the harshest condition, the reliability of the Japanese ACE-R was satisfactory for both the dementia and healthy control groups; the ICCs were 0.90 for the former and 0.77 for the latter. The reason for the discrepancy between the groups is that the healthy controls achieved high scores with a small variance among individuals. Unfortunately, comparisons cannot be made because the test-retest reliability has not been examined in previous studies. Cronbach's alpha coefficient was 0.88 in a combined analysis of the dementia and control groups. This result is consistent with previous studies $[6,8,10,11]$.

In the present study, the ACE- $\mathrm{R}$ total scores showed a moderate correlation with the CDR-SOB scores, which indicates that the Japanese version of the ACE-R is a valid tool for assessing the severity of dementia. A similar moderate correlation between the ACE-R total scores and the CDR-SOB scores was demonstrated in a previous study [10].

The diagnostic accuracy of the Japanese ACE-R for dementia was excellent, which is comparable with the results from previous studies of different language versions [7, 11]. Compared to the MMSE, the ACE-R covers a wider range of cognitive domains, such as semantic, visuoperceptual and executive functions. Consequently, the ACE-R offers the advantage of exploring different patterns of cognitive deterioration and, thus, may be suitable for the detection of non-memory-type dementias. The optimal cut-off score of the Japanese ACE-R was similar to the cut-off scores calculated in previous studies [6,9-12]. Although the sensitivity and specificity of the ACE-R for detecting dementia were not significantly higher compared to those obtained in the MMSE, the sensitivity may be high for FTLD, DLB and other types of dementia for which memory is relatively preserved. Moreover, this feature of the ACE-R may provide a significant clue to the differential diagnosis of the cause of dementia, as the performance profiles for the ACE-R domains differ among the causes. The ACE-R has 
been reported to have a good discrimination property between AD and FTLD $[6,9,10]$. Further studies are necessary to investigate the possibility that the ACE-R discriminates different causes of dementia.

Previous studies have shown significant effects of sex [7], age [6, 8] and education $[7,8$, 24 ] on the ACE-R total score, which is comparable with our study. When interpreting the ACE-R total score, these factors should be taken into consideration.

In conclusion, the present study demonstrates that the Japanese version of the ACE-R is a useful tool for the accurate detection of early stages of dementia in healthy elderly individuals. The test yields comparable scores among different language versions, which is advantageous for its use in international studies. Future research efforts are required to provide evidence for the discriminatory usefulness of the Japanese ACE-R across the various types of dementia.

\section{Acknowledgements}

This study was partly supported by a research grant from the Japan International Cooperation Agency to K.H.d.S.K. We wish to acknowledge the important cooperation we received from Mayumi Shinohara. We would like to express our gratitude for the support received from the Tohoku University Hospital, Saito Hospital, Minami Tohoku Hospital, Miyagi Hospital, Dainohara Elderly Welfare Center and Kameoka Elderly Welfare Center in Sendai. We sincerely thank the patients and the healthy volunteers for their participation in this study.

\section{Disclosure Statement}

The authors have no conflicts of interest to declare.

\section{References}

1 Hashimoto R: A Japanese version of the ACE-R, an appendix for the Japanese edition; in Mori E (ed): Japanese Edition of Hodges JR's Cognitive Assessment for Clinicians, ed 2. Tokyo, Shinko Igaku Shuppansha, 2010, pp 285-301.

-2 Folstein MF, Folstein SE, McHugh PR: Mini-Mental State: a practical method for grading the cognitive state of patients for the clinician. J Psychiatr Res 1975;12:189-198.

-3 Mohs RC, Rosen WG, Davis KL: The Alzheimer's disease assessment scale: an instrument for assessing treatment efficacy. Psychopharmacol Bull 1983;19:448-450.

-4 Burkart M, Heun R, Maier W, Benkert O: Dementia screening in routine clinical practice: a comparative analysis of MMSE, SIDAM and ADAS (in German). Nervenarzt 1998;69:983-990.

-5 Mathuranath PS, Nestor PJ, Berrios GE, Rakowicz W, Hodges JR: A brief cognitive test battery to differentiate Alzheimer's disease and frontotemporal dementia. Neurology 2000;55:1613-1620.

-6 Mioshi E, Dawson K, Mitchell J, Arnold R, Hodges JR: The Addenbrooke's Cognitive Examination Revised (ACE-R): a brief cognitive test battery for dementia screening. Int J Geriatr Psychiatry 2006; 21:1078-1085.

-7 Carvalho VA, Barbosa MT, Caramelli P: Brazilian version of the Addenbrooke Cognitive Examination-revised in the diagnosis of mild Alzheimer disease. Cog Behav Neurol 2010;23:8-13.

-8 Kwak YT, Yang Y, Kim GW: Korean Addenbrooke's Cognitive Examination Revised (K-ACER) for differential diagnosis of Alzheimer's disease and subcortical ischemic vascular dementia. Geriatr Gerontol Int 2010;10:295-301. 
-9 Alexopoulos P, Ebert A, Richter-Schmidinger T, Scholl E, Natale B, Aguilar CA, Gourzis P, Weih M, Perneczky R, Diehl-Schmid J, Kneib T, Forstl H, Kurz A, Danek A, Kornhuber J: Validation of the German revised Addenbrooke's Cognitive Examination for detecting mild cognitive impairment, mild dementia in Alzheimer's disease and frontotemporal lobar degeneration. Dement Geriatr Cogn Disord 2010;29:448-456.

-10 Torralva T, Roca M, Gleichgerrcht E, Bonifacio A, Raimondi C, Manes F: Validation of the Spanish version of the Addenbrooke's Cognitive Examination-Revised (ACE-R) (in Spanish). Neurologia 2011;26:351-356.

-11 Konstantinopoulou E, Kosmidis MH, Ioannidis P, Kiosseoglou G, Karacostas D, Taskos N: Adaptation of Addenbrooke's Cognitive Examination-Revised for the Greek population. Eur J Neurol 2011; 18:442-447.

-12 Terpening Z, Cordato NJ, Hepner IJ, Lucas SK, Lindley RI: Utility of the Addenbrooke's Cognitive Examination - Revised for diagnosis of dementia syndromes. Australas J Ageing 2011;30:113-118.

13 Mori E, Mitani Y, Yamadori A: Usefulness of a Japanese version of the Mini-Mental State Test in neurological patients (in Japanese). Jpn J Neuropsychol 1985;1:82-90.

14 Ito E, Hatta T: Reliability and validity of verbal fluency tasks (in Japanese). Jpn J Neuropsychol 2006; 22:146-152.

-15 Nishimoto T, Miyawari K, Ueda T, Une Y: Japanese normative set of 359 pictures. Behav Res Methods 2005;37:398-416.

16 American Psychiatric Association: Diagnostic and Statistical Manual of Mental disorders, ed 3, revised. Washington, American Psychiatric Association, 1987.

-17 McKhann G, Drachman D, Folstein M, Katzman R, Price D, Stadlan EM: Clinical diagnosis of Alzheimer's disease: report of the NINCDS-ADRDA work group under the auspices of the Department of Health and Human Service Task forces on Alzheimer's disease. Neurology 1984;34:939-944.

-18 Neary D, Snowden JS, Gustafson L, Passant U, Stuss D, Black S, Freedman M, Kertesz A, Robert PH, Albert M, Boone K, Miller BL, Cummings J, Benson DF: Frontotemporal lobar degeneration: a consensus on clinical diagnostic criteria. Neurology 1998;51:1546-1554.

-19 McKeith IG, Galasko D, Kosaka K, Perry EK, Dickson DW, Hansen LA, Salmon DP, Lowe J, Mirra SS, Byrne EJ, Lennox G, Quinn NP, Edwardson JA, Ince PG, Bergeron C, Burns A, Miller BL, Lovestone S, Collerton D, Jansen ENH, Ballard C, de Vos RAI, Wilcock GK, Jellinger KA, Perry RH: Consensus guidelines for the clinical and pathologic of dementia with Lewy bodies (DLB): report of the consortium on DLB international workshop. Neurology 1996;47:1113-1124.

-20 Emre M, Aarsland D, Brown R, Burn DJ, Duyckaerts C, Mizuno Y, Broe GA, Cummings J, Dickson DW, Gauthier S, Goldman J, Goetz C, Korczyn A, Lees A, Levy R, Litvan I, McKeith I, Olanow W, Poewe W, Quinn N, Sampaio C, Tolosa E, Dubois B: Clinical diagnosis criteria for dementia associated with Parkinson's disease. Mov Disord 2007;22:1687-1707.

-21 Litvan I, Agid Y, Calne D, Campbell G, Dubois B, Duvoisin RC, Goetz CG, Golbe LI, Grafman J, Growdon JH, Hallett M, Jankovic J, Quinn NP, Tolosa E, Zee DS: Clinical research criteria for the diagnosis of progressive supranuclear palsy (Steele-Richardson-Olszewski syndrome): report of the NINDS-SPSP international workshop. Neurology 1996;47:1-9.

22 Lang AE, Riley DE, Bergeron C: Cortical-basal ganglionic degeneration; in Calne DB (ed): Neurodegenerative Diseases. Philadelphia, Saunders, 1994, pp 877-894.

-23 Morris JC: The Clinical Dementia Rating (CDR): current version and scoring rules. Neurology 1993; 43:2412-2414.

24 Carvalho VA, Caramelli P: Addenbrooke's Cognitive Examination-Revised (ACE-R): Cross-cultural adaptation, normative data for cognitively preserved elderly and its applicability as a brief cognitive evaluation tool for mild probable Alzheimer's disease patients (in Portuguese). Master's thesis, University of São Paulo, School of Medicine, 2009. 